\title{
Green synthesis of zinc oxide nano-sized spherical particles using Terminalia chebula fruits extract for their photocatalytic applications
}

\author{
N. Rana $^{1} \cdot$ Subhash Chand ${ }^{1} \cdot$ Arvind K. Gathania $^{1}$
}

Received: 27 July 2015/ Accepted: 18 December 2015/Published online: 26 January 2016

(C) The Author(s) 2016. This article is published with open access at Springerlink.com

\begin{abstract}
The present study describes the green synthesis of $\mathrm{ZnO}$ nano-sized spherical particles (ZnO-NPs) using aqueous fruits extract of Terminalia chebula. The Structural, morphological and optical properties of green-synthesized ZnO-NPs are characterized by X-ray diffraction, Fourier transform infrared, field emission-scanning electron microscope, ultraviolet-visible and photoluminescence spectroscopy techniques. The results show that the synthesized nanoparticles have stable hexagonal wurtzite structure, and roughly spherical in shape. To explore the photocatalytic activity of the ZnO-NPs the photocatalytic degradation of rhodamine $\mathrm{B}(\mathrm{RhB})$ dye is investigated. The results reveal that $\mathrm{ZnO}-\mathrm{NPs}$ prepared through green synthesis route are found to be efficient in the degradation of RhB dye.
\end{abstract}

Keywords Green synthesis - Nanoparticles ·

Photocatalytic activity

\section{Introduction}

Nanostructures have attracted the attention of researchers because of their variety of anticipated future in the technology. Such type of structures involves advantage of sizeinduced changes in electronic, mechanical, chemical as well as optical properties from their bulk counterpart [1-6].

Zinc oxide $(\mathrm{ZnO})$ has gained the substantial interest of physicist, chemist and scientist because of its direct wide

Arvind K. Gathania

akgathania@yahoo.com

1 Department of Physics, National Institute of Technology, Hamirpur, H.P. 177 005, India band gap of $3.3 \mathrm{eV}$ at room temperature. $\mathrm{ZnO}$ particles with dimension in nano-range have shown their role in important application as solar cells, displays, sensors, photocatalysts, pharmaceutical, antimicrobial and cosmetic industries. These nanostructures can be prepared by physical, chemical and green synthesis routes [7-9]. The green synthesis route is the design of chemical products and processes which does not use and generate hazardous substances. It uses the biological materials which are easily extractable, eco-friendly and economical.

In green synthesis approach, a broad variety of biological materials has been explored, which acts as both reducing and stabilizing agents [10-13]. Ramesh et al. [14] have synthesized ZnO-NPs using an aqueous extract of Cassia Auriculata flower. Bhuyan et al. [15] have reported green synthesis of ZnO-NPs by utilizing the biocompatible leaves extract of Azadirachta indica of an average size of $9.6-25.5 \mathrm{~nm}$. As per our knowledge till date, we have not found any report available on the use of Terminalia chebula for the synthesis of ZnO-NPs.

Terminalia chebula (T. chebula) belongs to the family of Combretaceae [16]. It has been extensively used in ayurvedic medicine for its cardioprotective, antimicrobial, antioxidant, antidiabetic, gastrointestinal motility and wound healing activities. These activities are due to the presence of its various types of phytoconstituents such as polyphenols as hydrolysable tannin, phenolic acid, anthocyanins, terpenes, flavonoids, glycosides, etc., [16, 17]. Removal of toxic dye effluents from industrial wastewater is an important issue of environmental concern. In this regard, nanostructured semiconductor photocatalysts have attracted a great deal of interest for the decomposition of dye effluents to solve environmental problems [18-20]. $\mathrm{ZnO}-\mathrm{NPs}$ have been widely studied due to its biocompatible, biodegradable, nontoxic, photosensitive, and highly 
stable properties. The easy tuning to various surface morphology and high structural defects also help $\mathrm{ZnO}$ nanostructure for ideal photocatalytic applications [21-25].

In the present investigation, we have described the synthesis of ZnO-NPs by green synthesis method using the fruit extract of $T$. chebula. The photocatalytic activity of the green-synthesized $\mathrm{ZnO}-\mathrm{NPs}$ is systematically studied by observing the degradation of rhodamine $\mathrm{B}(\mathrm{RhB})$ dye.

\section{Experimental}

\section{Materials used}

The fresh $T$. chebula fruits are collected from the fallow land around National Institute of Technology, Hamirpur177005 (H.P.), India. The harvested fruits are washed thoroughly several times with deionised water, whipped with tissue paper and subsequently incised into small pieces. $10 \mathrm{~g}$ of it is added in $100 \mathrm{ml}$ of deionised water and boiled at $80{ }^{\circ} \mathrm{C}$ under continuous stirring. An aqueous extract is obtained after refluxing it for $2 \mathrm{~h}$. It is filtered through Whatman No. 1 filter paper and kept at $4{ }^{\circ} \mathrm{C}$ for further use. Zinc nitrate hexahydrate $\left[\mathrm{Zn}\left(\mathrm{NO}_{3}\right)_{2} \cdot 6 \mathrm{H}_{2} \mathrm{O}-\right.$ purity $99 \%$ ] is obtained from Merck-India. Methanol is purchased from Sigma-Aldrich (purity $\geq 99 \%$ ). RhB dye is obtained from Fisher scientific (purity $99+\%$ ). Deionized water used in preparation has a resistivity of $18.2 \mathrm{M} \Omega$ and obtained from Lab Pure Andel BIO-AGE. All chemicals are used without further purification.

\section{Preparation of $\mathrm{ZnO}$-NPs}

A solution of $\left(\mathrm{Zn}\left(\mathrm{NO}_{3}\right)_{2} \cdot 6 \mathrm{H}_{2} \mathrm{O}(0.1 \mathrm{M})\right.$ is prepared in $100 \mathrm{ml}$ of deionised water and refluxed at about $70{ }^{\circ} \mathrm{C}$ for 5 min under magnetic stirring to get a homogeneous solution. $30 \mathrm{~mL}$ of aqueous extract is added dropwise to it. The mixture is refluxed at $70{ }^{\circ} \mathrm{C}$ under continuous stirring for $2 \mathrm{~h}$. The reacted solution is allowed to dry in the hot air oven to yield pale white precipitates. Precipitates are washed with methanol and water to get rid of any unreacted materials and dried in air. Finally, it is annealed at $400{ }^{\circ} \mathrm{C}$ for $1 \mathrm{~h}$ in the furnace and used for further characterization.

\section{Characterization}

The crystal structure of the synthesized sample is investigated using X-ray diffraction (XRD, X'Pert Pro, Philips) with $\mathrm{Cu}-\mathrm{K}_{\alpha}$ radiation $(\lambda=1.5406 \AA)$. The morphology and elemental investigation are carried out using Field emission-scanning electron microscope (FE-SEM, SIGMA HV-Carl Zeiss) equipped with energy dispersive X-rays analysis (EDX) Bruker machine. Photoluminescence (PL) study is performed with an InVia Raman spectrophotometer (Renishaw) using $\mathrm{He}-\mathrm{Cd}$ laser with excitation wavelength at $325 \mathrm{~nm}$. The Fourier transform infrared (FTIR) spectrum is recorded using Perkin Elmer IR Spectrophotometer with $\mathrm{KBr}$ pellets over the range 400$4000 \mathrm{~cm}^{-1}$. The optical properties are analyzed using Ultraviolet-Visible (UV-Vis) spectrometer (PerkinElmer, model LAMBDA 750). The photocatalytic degradation of $\mathrm{RhB}$ in water solution is performed with green-synthesized $\mathrm{ZnO}-\mathrm{NPs}$ at room temperature. $\mathrm{ZnO}$-NPs provide an active reaction sites for the photocatalytic reaction. ZnO-NPs powder $\left(1 \mathrm{~g} \mathrm{~L}^{-1}\right)$ is suspended to $\mathrm{RhB}$ solution $(5,10,20$ and $30 \mathrm{ppm}$ ) and stirred in dark for $30 \mathrm{~min}$ to establish the adsorption-desorption equilibrium between the powder and the RhB dye molecules and then exposed to $30 \mathrm{~W}$ UV light. At regular irradiation time intervals, a series of samples are taken out and centrifuged to remove the suspended $\mathrm{ZnO}-\mathrm{NPs}$ and analyzed by a UV-Vis spectrophotometer to obtain the absorbance of the RhB solutions. The degradation efficiency $\mathrm{X}(\%)$ is calculated from absorption spectra using the following relation:

$X(\%)=\frac{\left(A_{0}-A_{\mathrm{t}}\right)}{A_{0}} \times 100$,

where $A_{0}$ and $A_{\mathrm{t}}$ represent the initial absorbance and the absorbance at certain time $t$, respectively.

\section{Results and discussion}

\section{The X-ray diffraction analysis}

Figure 1 shows the XRD patterns of as-prepared ZnO-NPs. All diffraction peaks positioned at $31.8^{\circ}, 34.5^{\circ}, 36.3^{\circ}$, $47.6^{\circ}, 56.6^{\circ}, 62.9^{\circ}, 66.4^{\circ}, 68.1^{\circ}, 69.2^{\circ}, 72.6^{\circ}$ and $77.2^{\circ}$ can be indexed to the (100), (002), (101), (102), (110), (103), (200), (112), (201), (004) and (202) planes of a $\mathrm{ZnO}$ hexagonal wurtzite structure. All peaks are in good agreement with standard diffraction data (JCPDS Card no.: 36-1451). This clearly confirms that ZnO-NP has been successfully synthesized by green synthesis route. In addition, the strong intensity of diffraction peaks indicates that the formed $\mathrm{ZnO}-\mathrm{NPs}$ are well crystallized at $400{ }^{\circ} \mathrm{C}$.

The broadening of the diffraction peaks clearly indicates the presence of nanoparticles in the sample. The average crystalline size of the green-synthesized $\mathrm{ZnO}-\mathrm{NPs}$ is calculated using Debye-Scherrer's formula [26]:

$D=\frac{0.9 \lambda}{\beta \cos \theta}$,

where $D$ is the crystallite size, $\lambda$ is the wavelength of $\mathrm{X}$-ray radiation, $\beta$ is the full width at half maximum of the diffraction peak (in radian), $\theta$ is the diffraction angle. The 
Fig. 1 XRD pattern of greensynthesized $\mathrm{ZnO}-\mathrm{NPs}$

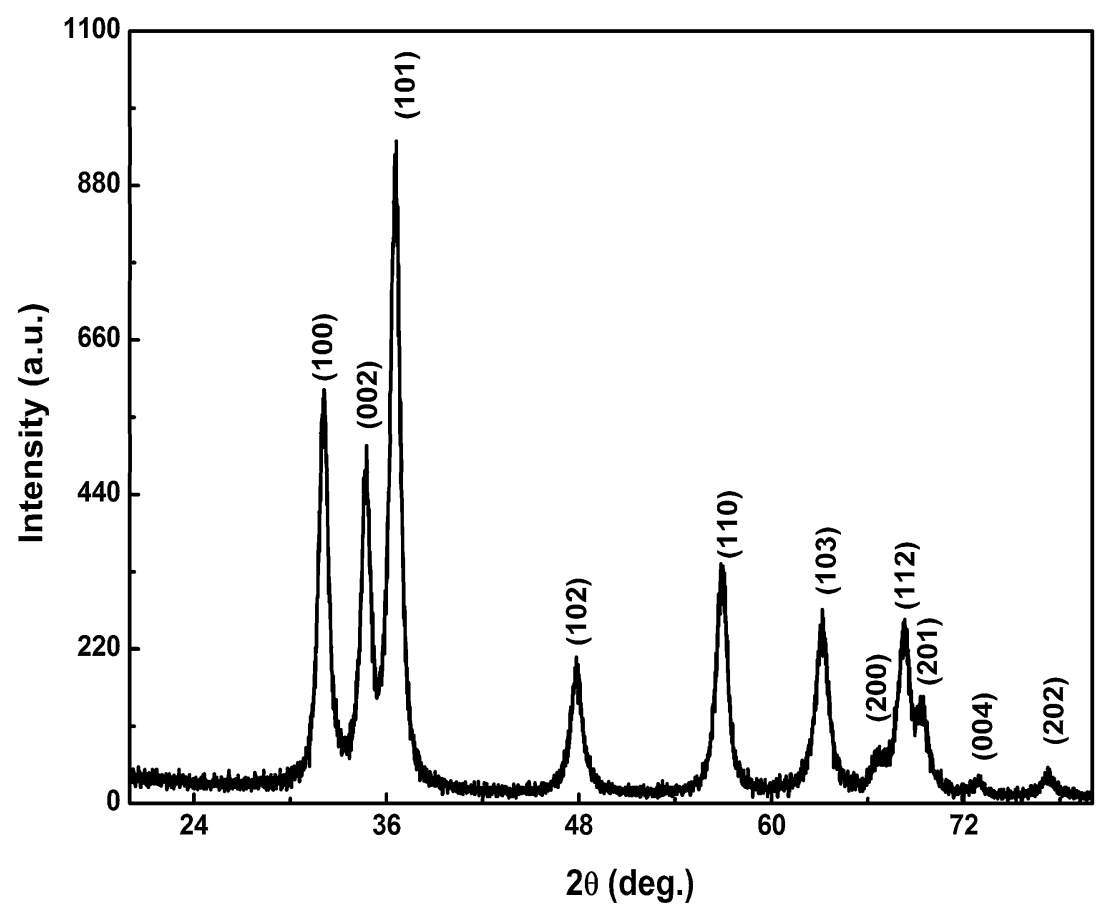

calculated value of the average crystallite size is $12 \mathrm{~nm}$. For hexagonal structure, the lattice constants $a$ and $c$ are obtained using equation:

$\frac{l}{d_{h k l}^{2}}=\frac{4}{3}\left(\frac{h+h k+k^{2}}{a^{2}}\right)+\frac{l^{2}}{c^{2}}$,

where $(h k l)$ are the Miller indices, and $d_{h k l}$ is inter-planar spacing. The calculated values of the lattice constants of ZnO-NPs are $a=3.2473 \AA$ and $c=5.1917 \AA$.

\section{Fourier transform infrared studies}

FT-IR spectroscopy measurements are carried out to confirm the presence/formation of $\mathrm{Zn}-\mathrm{O}$ band and to identify the phytoconstituents that are capped on ZnO-NPs surface. FT-IR spectrum of green-synthesized ZnO-NPs is shown in Fig. 2.

The wide absorption band that appeared at $3446 \mathrm{~cm}^{-1}$ is characteristic of the $\mathrm{O}-\mathrm{H}$ vibrations. It indicates the presence of phenolic hydroxyl group, which is the major phytoconstituents of $T$. chebula. The band $\sim 1631 \mathrm{~cm}^{-1}$ is due to the carbonyl group $(\mathrm{C}=\mathrm{O})$ which reveals the existence of phenolic acids and tannins. The presence of the band at $1400 \mathrm{~cm}^{-1}$ belongs to aromatic $\mathrm{C}=\mathrm{C}$ stretching vibrations. In addition, the band observed at $1048 \mathrm{~cm}^{-1}$ reflects $\mathrm{C}-\mathrm{O}$ group, which is associated with carboxylic acid and esters. The sharp band positioned at $460 \mathrm{~cm}^{-1}$ represents the bonding between $\mathrm{Zn}$ and $\mathrm{O}$. Hence, FT-IR study reveals that the phytoconstituents of T. chebula protect the ZnO-NPs from aggregation by stabilizing the surface of nanoparticles during the synthesis process.

\section{Ultraviolet-visible spectroscopy}

The optical band gap $\left(E_{\mathrm{g}}\right)$ of the $\mathrm{ZnO}$-NPs sample is estimated using the Tauc's equation which demonstrates a relationship between absorption coefficient $(\alpha)$ and the incident photon energy $(h v)$ as follows [27]:

$\alpha h v=\beta\left(h v-E_{\mathrm{g}}\right)^{n}$,

where the exponent $n$ is $1 / 2,3 / 2,2,3$ (for allowed direct, forbidden direct, allowed indirect and forbidden indirect transitions, respectively). Therefore, in case of direct band gap the allowed transitions are given using the Eq. (4) as:

$\alpha h v=\beta\left(h v-E_{\mathrm{g}}\right)^{1 / 2}$,

Figure 3 shows the $(\alpha h v)^{2}$ versus $h v$ plot using the data from optical absorbance spectra. An extrapolation of the linear portion of the plot to the $x$-axis $\left((\alpha h v)^{2}=0\right)$ gives the value of the $E_{\mathrm{g}}$. The obtained value of optical band gap is $3.22 \mathrm{eV}$.

\section{Photoluminescence studies}

Figure 4 depicts the PL spectra of ZnO-NPs. The inset in Fig. 4 shows that the spectrum has a low intensity near band emission peak at $396 \mathrm{~nm}$. It originated from the annihilation of excitons [28, 29]. Figure 4 shows a broad as well as prominent emission peak in the visible region. The 
Fig. 2 FT-IR spectrum of green-synthesized $\mathrm{ZnO}-\mathrm{NPs}$

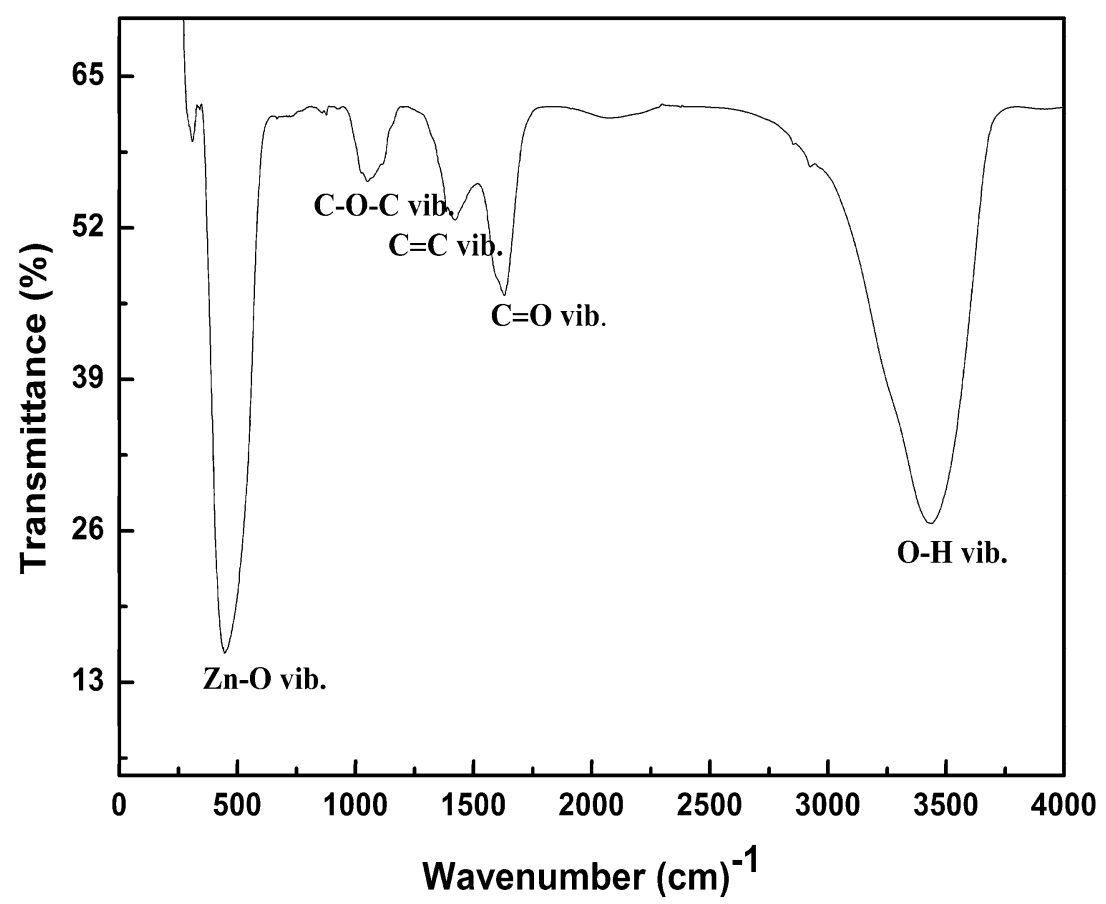

Fig. 3 Tauc's plot of greensynthesized $\mathrm{ZnO}$-NPs. The inset shows UV-Vis absorption spectrum of $\mathrm{ZnO}-\mathrm{NPs}$

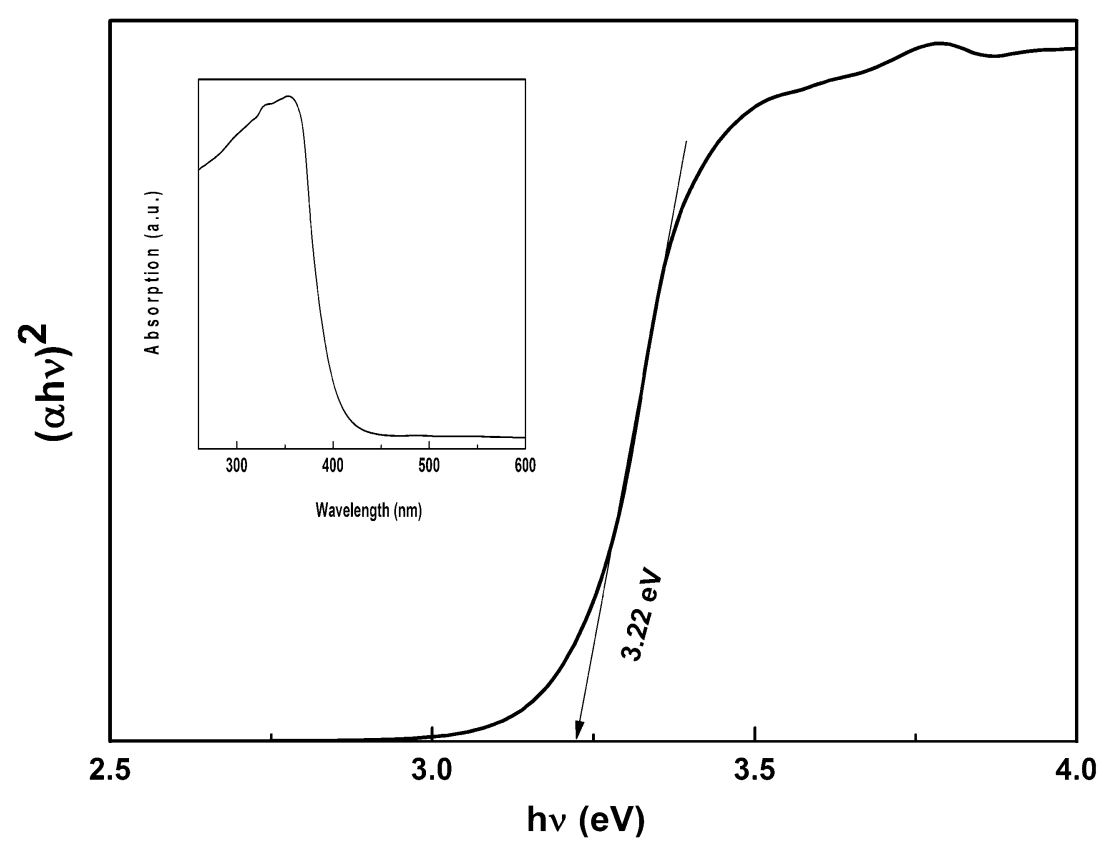

Gaussian fit to the peak in visible region gives three emission peaks centered at 575, 657 and $719 \mathrm{~nm}$. It has been shown that the presence of emission peaks in the PL spectra in the visible region is due to the presence of defect levels below the conduction band. The native defects in the $\mathrm{ZnO}$ wideband gap semiconductor materials result generation of deep levels within the forbidden band gap. These defects are assigned to zinc interstitials, zinc vacancies, oxygen interstitial and oxygen vacancies [30, 31]. Moreover, these defects act as active sites for photogenerated electrons and holes. These photogenerated electron and holes avoid recombination by occupying sites at the $\mathrm{ZnO}$ surface and are remain available to degrade pollutant by generating highly oxidative radical to show photocatalytic characteristics. Zhan et al. [32-35] examine the PL spectra of $\mathrm{ZnO}$ films and found emission in the ultraviolet and the visible regions. Near band edge is interpreted due to the exciton recombination and the deep level visible light emission is due to various point defects. A similar PL spectrum has also been observed for fern-like $\mathrm{ZnO}$ 
Fig. 4 Photoluminescence spectra of green-synthesized $\mathrm{ZnO}-\mathrm{NPs}$

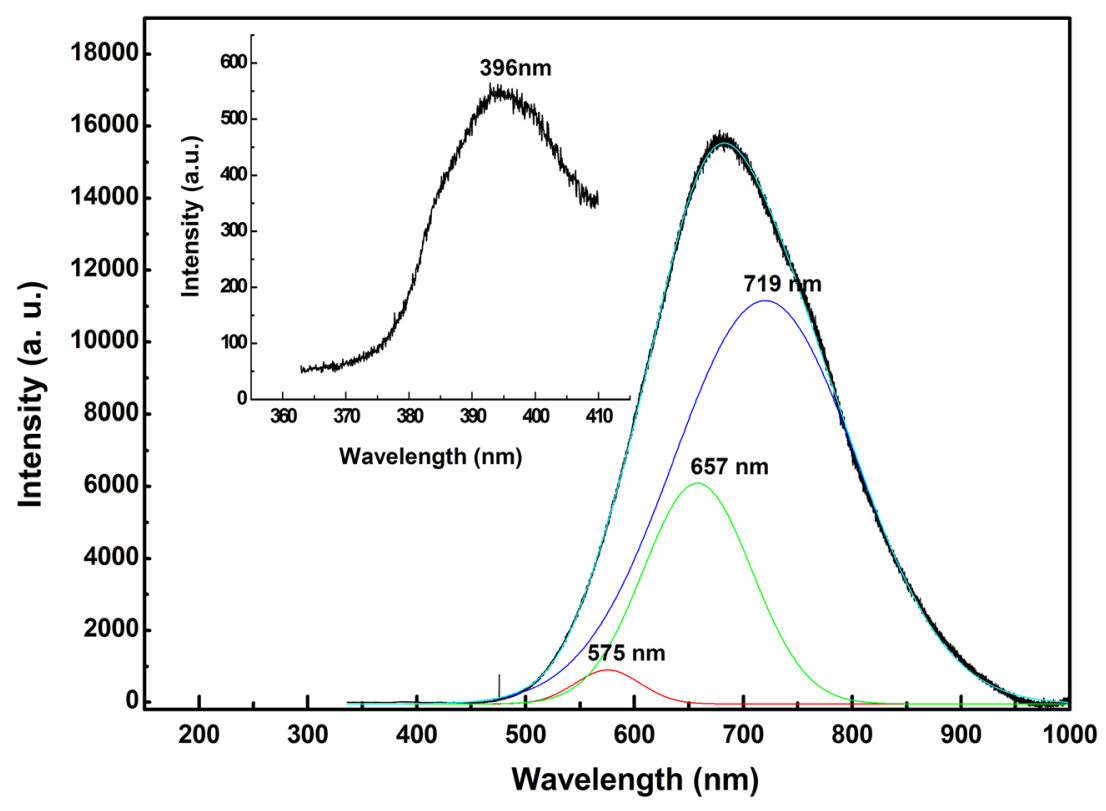

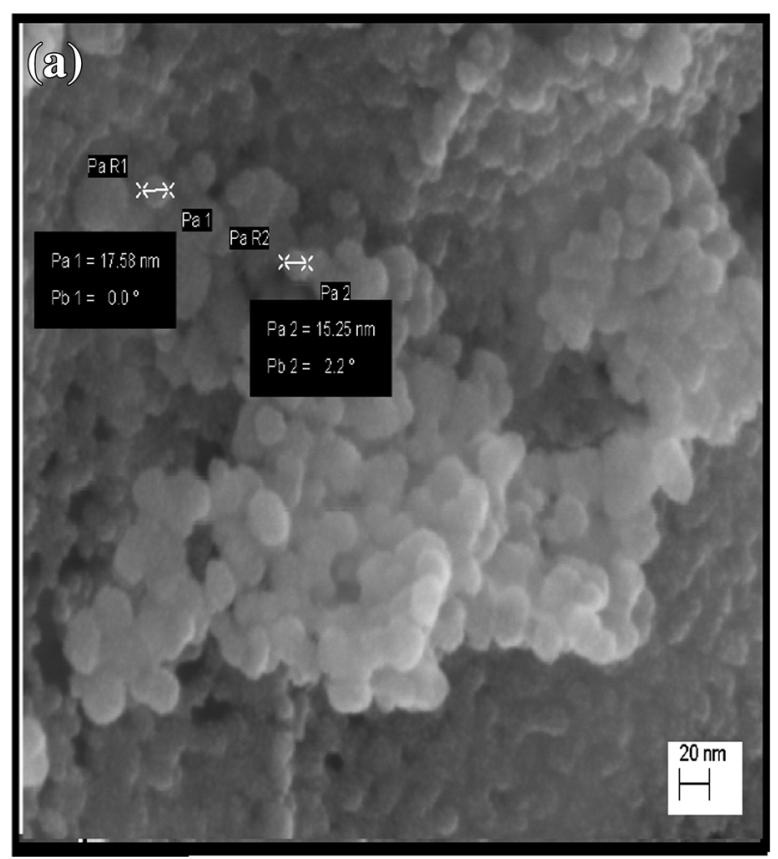

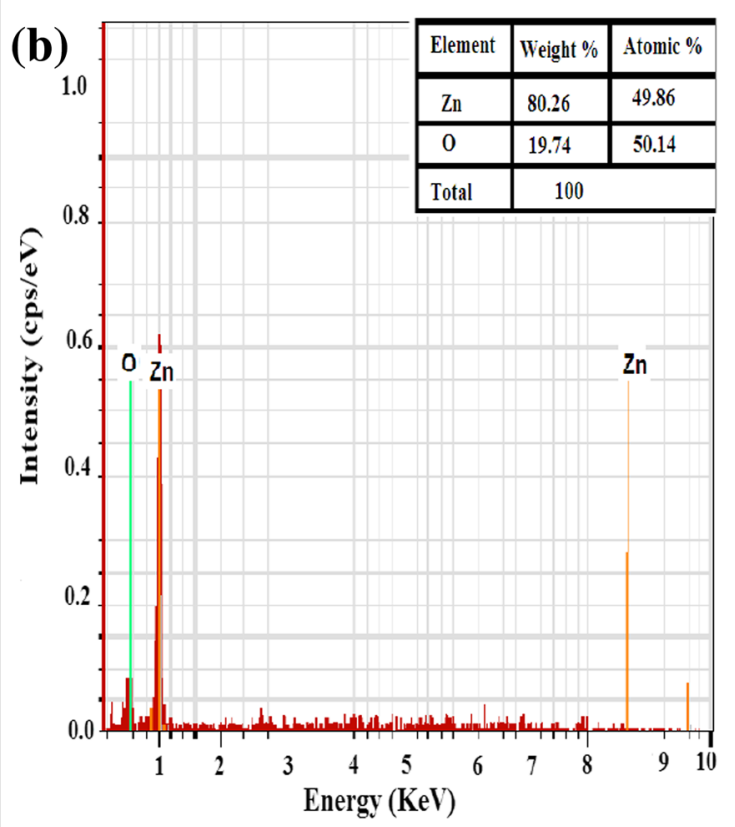

Fig. 5 a FE-SEM images and b EDX spectrum of green-synthesized ZnO-NPs

nanoleaves by Ma et al. [36]. It is confirmed from EDX spectrum that there is no contamination in the prepared samples. Hence, the emission in visible region is due to the presence of defects only.

\section{Morphological and elemental analysis}

FE-SEM images of the biosynthesized $\mathrm{ZnO}-\mathrm{NPs}$ are shown in Fig. 5a. It is observed that the morphology of $\mathrm{ZnO}-\mathrm{NPs}$ is almost spherical in nature. The size of $\mathrm{ZnO}-\mathrm{NPs}$ observed in the FE-SEM images is consistent with the
XRD results. The Fig. 5b shows the EDX spectrum of ZnO-NPs. It clearly confirms the presence of zinc and oxygen elements in the sample. No peaks belonging to any other element is found in the spectrum, which confirms that the prepared sample is free from impurity.

\section{Photocatalytic activity}

Figure 6a illustrates the temporal evolution of optical absorption spectra of the $5 \mathrm{ppm} \mathrm{RhB}$ dye aqueous solutions with $\mathrm{ZnO}$-NPs $\left(1 \mathrm{~g} \mathrm{~L}^{-1}\right)$ photocatalyst. It is observed that 
the intensity of the absorption peak at $\approx 553 \mathrm{~nm}$ decreases with the increase of irradiation time. It indicates the degradation of $\mathrm{RhB}$ dye molecules with $\mathrm{ZnO}-\mathrm{NPs}$ photocatalytic activity. It also shows that the ZnO-NPs can degrade the pollutant drastically in the $5 \mathrm{~h}$. It reflects that these nanoparticles are stable for photocatalytic applications. The underlying mechanism of the photocatalytic degradation of $\mathrm{RhB}$ by the $\mathrm{ZnO}-\mathrm{NPs}$ under irradiation can be explained on the basis of photogeneration of electronhole pairs (excitons) in $\mathrm{ZnO}-\mathrm{NP}$. These photogenerated charge carriers then move freely to the surface of the $\mathrm{ZnO}$ NPs and initiate redox reactions water $\left(\mathrm{H}_{2} \mathrm{O}\right)$ and oxygen $\left(\mathrm{O}_{2}\right)$ molecules. The holes in the valence band can act as the site for strong oxidation. They can oxidize $\mathrm{H}_{2} \mathrm{O}$ molecules and hydroxyl $\left(\mathrm{OH}^{-}\right)$groups to generate highly reactive hydroxyl $\left(\mathrm{OH}^{-}\right)$radical and $\mathrm{H}^{+}$ion. $\mathrm{O}_{2}$ molecules adsorbed on the surface will be reduced by the electrons in the conduction band to form superoxide anion $\left(\mathrm{O}_{2}^{-}\right)$radicals, which react with $\mathrm{H}^{+}$to generate hydrogen peroxide $\left(\mathrm{HO}_{2}\right)$ radicals. These $\mathrm{HO}_{2}$ radicals react with electrons and $\mathrm{H}^{+}$ions to produce molecules of $\mathrm{H}_{2} \mathrm{O}_{2}$. In addition, oxygen vacancies in the semiconductor crystals act as electron donors. The additional electrons induced by these vacancies will promote the reactions to further yield $\mathrm{OH}^{\text {. }}$ radicals. These highly reactive $\mathrm{OH}$ radicals and $\mathrm{H}_{2} \mathrm{O}_{2}$ molecules have the strong oxidative potential for partial or complete decomposition of various organic, inorganic and microbial contaminants adsorbed on the photocatalyst surface [37-40].
The effect of initial RhB concentration on the photocatalytic degradation is studied by varying the concentration from 5 to $30 \mathrm{ppm}$ against fixed $\mathrm{ZnO}$ nanoparticle load of $1 \mathrm{~g} \mathrm{~L}^{-1}$. The photodegradation of $\mathrm{RhB}$ decreases with the increase in the initial $\mathrm{RhB}$ concentration as shown in Fig. 6b. After $5 \mathrm{~h}$ of photocatalytic reaction, the extent of dye degradation is $70,60,15$ and $5 \%$ for initial dye concentration of $5,10,20$ and $30 \mathrm{ppm}$, respectively, as shown in Fig. 7b. The kinetics of the photocatalytic degradation reaction of $\mathrm{RhB}$ could be described by pseudofirst-order kinetics [32]:

$\ln \frac{C_{0}}{C_{\mathrm{t}}}=k t$

where $C_{0}$ is the initial dye concentration and $C_{\mathrm{t}}$ is the concentration of dye at different time intervals, $k$ is the first-order rate constant. As $A_{0} / A_{\mathrm{t}}$ corresponds to $C_{0} / C_{\mathrm{t}}$, the slope of the straight line from $\ln \left(A_{0} / A_{\mathrm{t}}\right)$ versus $t$ plot gives the value of the rate constants (Fig. 7a).

The rate constants for 5, 10, 20 and $30 \mathrm{ppm}$ of $\mathrm{RhB}$ dye concentrations are estimated to be $0.228,0.183,0.033$ and $0.009 \mathrm{~h}^{-1}$, respectively. The decrease in the value of rate constant with the increase in $\mathrm{RhB}$ concentration is due to the decrease in the availability of active reaction sites for the photocatalytic reaction. Also with the increase in the number of dye molecules, the path length of photons entering the solution decreases and fewer photons reach the catalyst surface, which results in the decrease in the generation reactive hydroxyl and superoxide radicals.
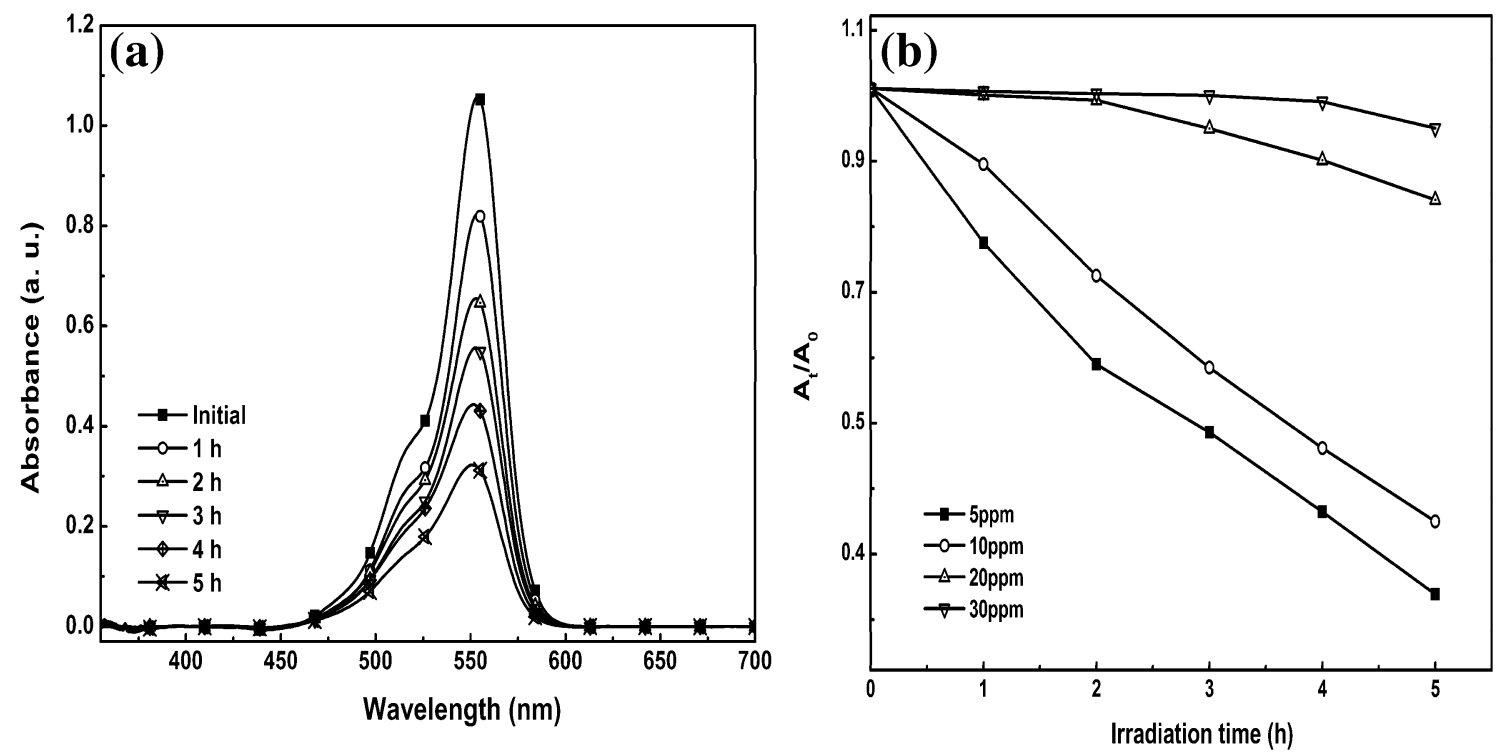

Fig. 6 a The temporal evolution of the absorption spectra of $5 \mathrm{ppm} \mathrm{RhB}$ aqueous solution in the presence of $\mathrm{ZnO}$ nanoparticles. b The photodegradation time profile of $A_{\mathrm{t}} / A_{0}$ for different initial dye concentration treated with $\mathrm{ZnO}-\mathrm{NPs}\left(1 \mathrm{~g} \mathrm{~L}^{-1}\right)$ photocatalyst 

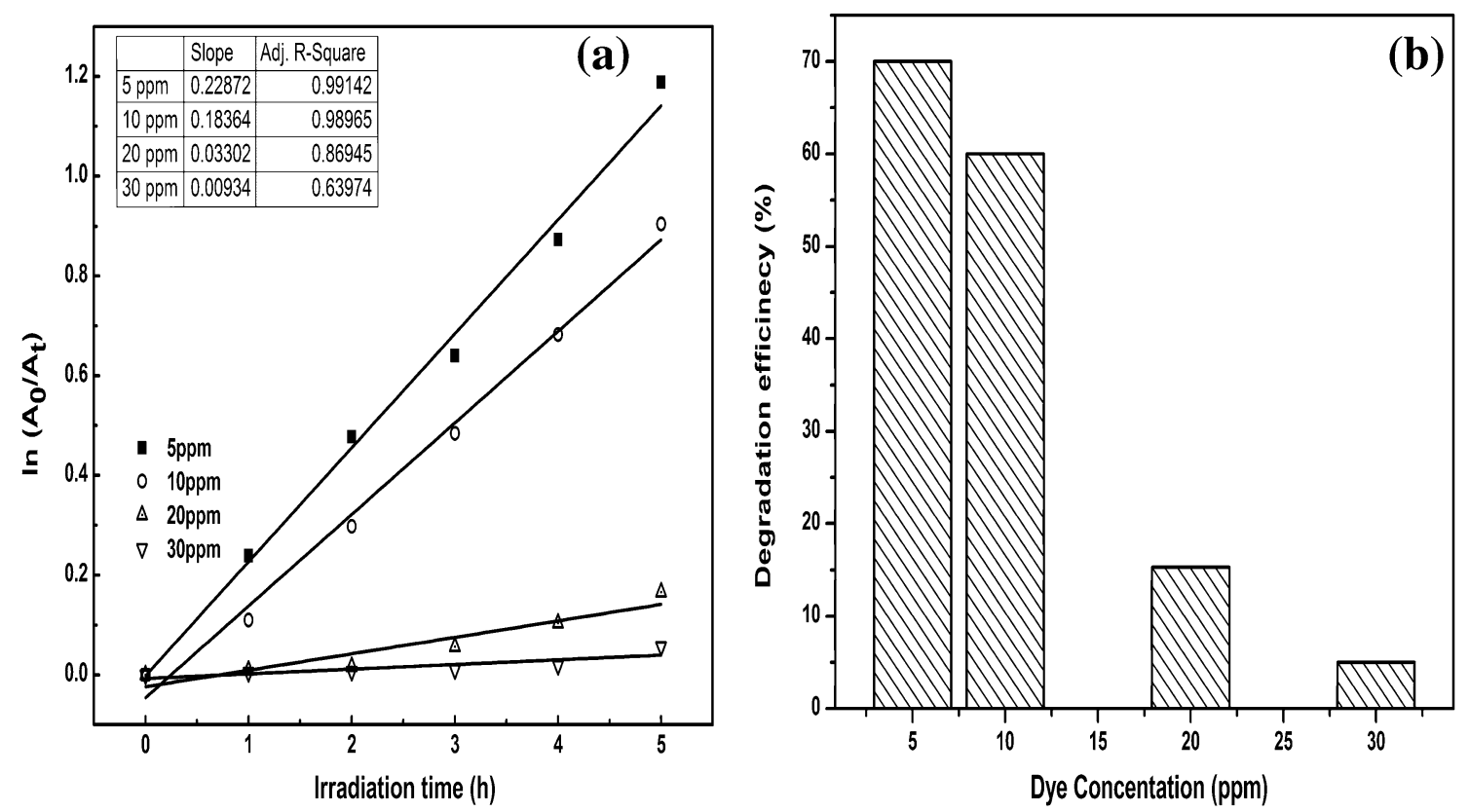

Fig. 7 a The first-order kinetic model fit for different dye concentration and the inset table shows the corresponding slope and adj. R-square. b Extent of degradation of $\mathrm{RhB}$ dye for different dye concentrations after $5 \mathrm{~h}$ of irradiation

\section{Conclusion}

In this study, we have successfully synthesized $\mathrm{ZnO}-\mathrm{NPs}$ via green synthesis route using aqueous fruits extract of $T$. chebula. The formation of $\mathrm{ZnO}-\mathrm{NPs}$ is confirmed by $\mathrm{XRD}$, FE-SEM, EDX, FT-IR, UV-Vis spectra and PL measurements. The photocatalytic study shows an effective photodegradation of $\mathrm{RhB}$ dye by the green-synthesized $\mathrm{ZnO}$ NPs. Thus, the eco-friendly and non-toxic green-synthesized $\mathrm{ZnO}-\mathrm{NPs}$ can be employed as a potential semiconductor photocatalyst for practical applications in wastewater treatment.

Acknowledgments Authors thank NIT-Hamirpur for providing experimental facilities and financial assistance to carry out the present work. Authors thank CMSE-NIT Hamirpur for providing characterization facilities. Useful comments suggested by reviewers are gratefully acknowledged.

\section{Compliance with ethical standards}

Conflict of interest The authors declare that they have no conflict of interest.

Open Access This article is distributed under the terms of the Creative Commons Attribution 4.0 International License (http://crea tivecommons.org/licenses/by/4.0/), which permits unrestricted use, distribution, and reproduction in any medium, provided you give appropriate credit to the original author(s) and the source, provide a link to the Creative Commons license, and indicate if changes were made.

\section{References}

1. Rao, C.N.R., Cheetham, A.K.: Science and technology of nanomaterials: current status and future prospects. J. Mater. Chem. 11, 2887-2894 (2001)

2. Sharma, A., Singh, B.P., Gathania, A.K.: Synthesis and characterization of dodecanethiol-stabilized gold nanoparticles. Indian J. Pure Appl. Phys. 52, 93-100 (2014)

3. Dhiman, N., Singh, B.P., Gathania, A.K.: Fabrication and optical study of dye doped $\mathrm{TiO}_{2}-\mathrm{SiO}_{2}$ multilayer colloidal structures. Colloids Surf. A Physicochem. Eng. Asp. 409, 69-73 (2012)

4. Thakur, S., Gathania, A.K.: Fluorescence study of Eu-YVO nano-phosphors as a function of calcination temperature and excitation wavelengths. J. Fluoresc. 25, 657-661 (2015)

5. Rana, N., Chand, S., Gathania, A.K.: Band gap engineering of $\mathrm{ZnO}$ by doping with Mg. Phys. Scr. 90(1-6), 085502 (2015). doi:10.1088/0031-8949/90/8/085502

6. Rana, N., Chand, S., Gathania, A.K.: Tailoring the structural and optical properties of $\mathrm{ZnO}$ by doping with $\mathrm{Cd}$. Ceram. Int. 41, 12032-12037 (2015)

7. Ozgur, U., Alivov, Y.I., Liu, C., Teke, A., Reshchikov, M.A., Dogan, S., Avrutin, V., Cho, S.J., Morkoc, H.: A comprehensive review of $\mathrm{ZnO}$ materials and devices. J. Appl. Phys. 98, 041301-041403 (2005)

8. Djurisic, A.B., Chen, X., Leung, Y.H., Ng, A.M.C.: ZnO nanostructures: growth, properties and applications. J. Mater. Chem. 22, 6526-6535 (2012)

9. Wang, Z.L.: Zinc oxide nanostructures: growth, properties and applications. J. Phys. Condens. Matter. 16, R829-R858 (2004)

10. Sharma, A., Dhiman, N., Singh, B.P., Gathania, A.K.: Green synthesis of gold nanoparticles using extracts of Artocarpus Lakoocha fruit and its leaves, and Eriobotrya Japonica leaves. 
Mater. Res. Express 1(1-10), 025042 (2014). doi:10.1088/2053$1591 / 1 / 2 / 025042$

11. Iravani, S.: Green synthesis of metal nanoparticles using plants. Green Chem. 13, 2638-2650 (2011)

12. Nath, D., Banerjee, P.: Green nanotechnology-a new hope for medical biology. Environ. Toxicol. Pharmacol. 36, 997-1014 (2013)

13. Duan, H., Wang, D., Li, Y.: Green chemistry for nanoparticle synthesis. Chem. Soc. Rev. 44, 5778-5792 (2015)

14. Ramesh, P., Rajendran, A., Meenakshisundaram, M.: Green synthesis' of zinc oxide nanoparticles using flower extract Cassia auriculata. J. Nanosci. Nanotechnol. 2, 41-45 (2014)

15. Bhuyan, T., Mishra, K., Khanuja, M., Prasad, R., Varma, A.: Biosynthesis of zinc oxide nanoparticles from Azadirachta indica for antibacterial and photocatalytic applications. Mater. Sci. Semicond. Process. 32, 55-61 (2015)

16. Bag, A., Bhattacharyya, S.K., Chattopadhyay, R.R.: The development of Terminalia chebula Retz. (Combretaceae) in clinical research. Asian Pac. J. Trop. Biomed. 3, 244-252 (2013)

17. Pfundstein, B., El Desouky, S.K., Hull, W.E., Haubner, R., Erben, G., Owen, R.W.: Polyphenolic compounds in the fruits of Egyptian medicinal plants (Terminalia bellerica Terminalia chebula and Terminalia horrida): characterization, quantitation and determination of antioxidant capacities. Phytochemistry 71, 1132-1148 (2010)

18. Devan, R.S., Patil, R.A., Lin, J.H., Ma, Y.R.: One-dimensional metal- oxide nanostructures: recent developments in synthesis, characterization, and applications. Adv. Funct. Mater. 22, 3326-3370 (2012)

19. Abe, R.: Recent progress on photocatalytic and photoelectrochemical water splitting under visible light irradiation. J. Photochem. Photobiol. C Photochem. Rev. 11, 179-209 (2010)

20. Tong, H., Ouyang, S.X., Bi, Y.P., Umezawa, N., Oshikiri, M., Ye, J.H.: Nano-photocatalytic materials: possibilities and challenges. Adv. Mater. 24, 229-251 (2011)

21. Mills, A., Hunte, S.L.: An overview of semiconductor photocatalysis. J. Photochem. Photobiol. A Chem. 108, 1-35 (1997)

22. Hirota, K., Sugimoto, M., Kato, M., Tsukagoshi, K., Tanigawa, T., Sugimoto, H.: Preparation of zinc oxide ceramics with a sustainable antibacterial activity under dark conditions. Ceram. Int. 36, 497-506 (2010)

23. Jang, E.S., Won, J.H., Hwang, S.-J., Choy, J.-H.: Fine tuning of the face orientation of $\mathrm{ZnO}$ crystals to optimize their photocatalytic activity. Adv. Mater. 18, 3309-3312 (2006)

24. Kohan, A.F., Ceder, G., Morgan, D., Van de Walle, C.G.: Firstprinciples study of native point defects in ZnO. Phys. Rev. B 61, 15019-15027 (2000)

25. Liu, Y., Kang, Z.H., Chen, Z.H., Shafiq, I., Zapien, J.A., Bello, I., Zhang, W.J., Lee, S.T.: Synthesis, characterization, and photocatalytic application of different $\mathrm{ZnO}$ nanostructures in array configurations. Cryst. Growth Des. 9, 3222-3227 (2009)
26. Cullity, B.D.: Elements of X-ray diffraction: a practical approach. Addison-Wesley, California (1956)

27. Tauc, J., Menthe, A.: States in the gap. J. Non-Cryst. Solids 8, 569-585 (1972)

28. Kong, Y.C., Yu, D.P., Zhang, B., Fang, W., Feng, S.Q.: Ultraviolet-emitting $\mathrm{ZnO}$ nanowires synthesized by a physical vapor deposition approach. Appl. Phys. Lett. 78, 407-409 (2001)

29. Wu, K., He, H., Lu, Y., Huang, J., Ye, Z.: Dominant free exciton emission in $\mathrm{ZnO}$ nanorods. Nanoscale 4, 1701-1706 (2012)

30. Ohtomo, A., Kawasaki, M., Koida, T., Masubuchi, K., Koinuma, H., et al.: $\mathrm{Mg}_{\mathrm{x}} \mathrm{Zn}_{1-\mathrm{x}} \mathrm{O}$ as a II-VI widegap semiconductor alloy. Appl. Phys. Lett. 72, 2466-2668 (1998)

31. Yang, L.L., Zhao, Q.X., Willander, M., Yang, J.H., Ivanov, I.: Annealing effects on optical properties of low temperature grown ZnO nanorod arrays. J. Appl. Phys. 105(1-7), 053503 (2009)

32. Zhan, P., Wang, W., Liu, C., Hu, Y., Li, Z., Zhang, Z., et al.: Oxygen vacancy-induced ferromagnetism in un-doped $\mathrm{ZnO}$ thin films. J. Appl. Phys. 111(1-5), 033501 (2012)

33. Zhan, P., Wang, W., Xie, Z., Li, Z., Zhang, Z., Zhang, P., et al.: Substrate effect on the room-temperature ferromagnetism in undoped ZnO films. Appl. Phys. Lett. 101(1-4), 031913 (2012)

34. Zhan, P., Xie, Z., Li, Z., Wang, W., Zhang, Z., Li, Z., et al.: Origin of the defects-induced ferromagnetism in un-doped $\mathrm{ZnO}$ single crystals. Appl. Phys. Lett. 102(1-5), 071914 (2013)

35. Zhan, P., Wang, W., Xie, Q., Li, Z., Zhang, Z.: Enhanced roomtemperature ferromagnetism in un-doped $\mathrm{ZnO}$ thin films by thermal annealing in a strong magnetic field. J. Appl. Phys. 111(1-5), 103524 (2012)

36. Ma, Q.L., Xiong, R., Zhai, B., Huang, Y.M.: Ultrasonic synthesis of fern-like $\mathrm{ZnO}$ nanoleaves and their enhanced photocatalytic activity. Appl. Surf. Sci. 324, 842-848 (2015)

37. Raza, W., Haque, M.M., Muneer, M.: Synthesis of visible light driven $\mathrm{ZnO}$ : characterization and photocatalytic performance. Appl. Surf. Sci. 322, 215-224 (2014)

38. Fang, Y., Li, Z., Xu, S., Han, D., Lu, D.: Optical properties and photocatalytic activities of spherical $\mathrm{ZnO}$ and flower-like $\mathrm{ZnO}$ structures synthesized by facile hydrothermal method. J. Alloys Compd. 575, 359-363 (2013)

39. Wahab, R., Khan, F., Lutfullah, B., Singh, R.B., Kaushik, N.K., Ahmad, J., Siddiqui, M.A., Saquib, Q., Ali, B.A., Khan, S.T., Musarrat, J., Al-Khedhairy, A.A.: Utilization of photocatalytic $\mathrm{ZnO}$ nanoparticles for deactivation of safranine dye and their applications for statistical analysis. Phys. E 69, 101-108 (2015)

40. Rana, N., Chand, S., Gathania, A.K.: Synthesis and characterization of flower-like $\mathrm{ZnO}$ structures and their applications in photocatalytic degradation of Rhodamine B dye. J. Mater. Sci. Mater. Electron. (2015). doi:10.1007/s10854-015-4051-7 